\title{
Ionizing radiation as preconditioning against transient cerebral ischemia in rats
}

\author{
Natália Kokošová ${ }^{1}$, Viera Danielisová2 ${ }^{2}$ Beňadik Šmajda ${ }^{1}$ and Jozef Burda ${ }^{2}$ \\ ${ }^{1}$ Department of Animal Physiology, Institute of Biology and Ecology, Faculty of Science, P. J. Šafárik University, Šrobárova 2, \\ 04001 Košice, Slovak Republic \\ ${ }^{2}$ Neurobiological Institute, Slovak Academy of Sciences, Šoltésovej 4, 04001 Košice, Slovak Republic
}

\begin{abstract}
Induction of ischemic tolerance (IT), the ability of an organism to survive an otherwise lethal ischemia, is the most effective known approach to preventing postischemic damage. IT can be induced by exposing animals to a broad range of stimuli. In this study we tried to induce IT of brain neurons using ionizing radiation (IR). A preconditioning (pre-C) dose of 10, 20, 30 or 50 Gy of gamma rays was used 2 days before an $8 \mathrm{~min}$ ischemia in adult male rats. Ischemia alone caused the degeneration of almost one half of neurons in CA1 region of hippocampus. However, a significant decrease of the number of degenerating neurons was observed after higher doses of radiation (30 and $50 \mathrm{~Gy})$. Moreover, ischemia significantly impaired the spatial memory of rats as tested in Morris's water maze. In rats with a $50 \mathrm{~Gy}$ pre-C dose, the latency times were reduced to values close to the control level. Our study is the first to reveal that IR applied in sufficient doses can induce IT and thus allow pyramidal CA1 neurons to survive ischemia. In addition, we show that the beneficial effect of IR pre-C is proportional to the radiation dose.
\end{abstract}

Key words: Ischemia - Preconditioning - Ionizing radiation - Hippocampus - Morris's water maze

Abbreviations: FJB, Fluoro-Jade B; IR, ionizing radiation; Ipre-C, ischemic preconditioning; IT, ischemic tolerance; MWM, Morris's water maze; pre-C, preconditioning.

\section{Introduction}

One of the basic attributes of living things is adaptability to unfavourable conditions. When exposed to sub-lethal environmental changes the majority of living organisms acquire transient tolerance to a stimulus that would be otherwise lethal (Kirino 2002). The ability to survive an otherwise lethal ischemia, denoted as ischemic tolerance (IT), can be induced by exposition of the animal to a sub-lethal stimulus - ischemic preconditioning (Ipre-C). This phenomenon is used in some neuroprotective strategies trying to abate the consequences of ischemic stroke, which currently represents

Correspondence to: Natália Kokošová, Department of Animal Physiology, Institute of Biology and Ecology, Faculty of Science, P. J. Šafárik University, Šrobárova 2, 04001 Košice, Slovak Republic

E-mail: kokosova.natalia@gmail.com the third leading cause of death and disability in the world (Lehotsky 2009).

Early papers on Ipre-C/IT in the myocardium and the brain were published by Murry et al. (1986) and by Schurr et al. (1986). Burda et al. (2003) have shown, that the optimal acquisition of IT of brain neurons consists of an initial sub-lethal impulse, followed by a maturation period of two (or more) days, after which neurons are able to survive a devastating ischemic attack.

Ischemic injury is usually not manifested in a diffuse uniform manner, but rather in the selective damage of the brain's sites with higher vulnerability (Pulsinelli and Brierley 1979; Pulsinelli et al. 1982). The hippocampus, the brain structure involved in declarative, spatial and contextual memory, is particularly sensitive and vulnerable to ischemic damage. Transient ischemia produced by temporary blood deprivation of the brain results in insidious delayed degeneration of specific vulnerable pyramidal neurons within the 
CA1 region of the hippocampus (Kirino 1982; Pulsinelli et al. 1982). Ipre-C affords robust protection of CA1 neurons against a subsequent severe ischemic challenge. The protection lasts only $2-3 \mathrm{~h}$, but reappears $24 \mathrm{~h}$ after the preconditioning (pre-C) stimulus (Riksen et al. 2004).

The leading hypothesis of the mechanisms of ischemic neuronal damage is based on oxidative damage mediated by reactive oxygen species (ROS) leading to neurodegeneration (Liu et al. 1993a). During cerebral ischemia, a number of events such as a rapid decrease in ATP-levels, calcium release from intracellular stores, loss of ion homeostasis, excitotoxicity, changes of enzymatic activities, arachidonic acid release, mitochondrial dysfunction, acidosis and edema predispose the brain to the formation of ROS. In the course of reperfusion, events associated with the return of the blood flow to the previously ischemic brain tissue result in an overproduction of ROS (McDonald and Stoodley1998).

Enzymatic defense against activated oxygen species involves cooperative action of intracellular antioxidant enzymes: cytosolic copper-zinc-superoxide dismutase (CuZnSOD), mitochondrial mangane-superoxide dismutase (MnSOD), glutathione peroxidase (GSH-Px) and catalase (CAT) that are present in cytosol and in peroxisomes. SODs metabolize superoxide anion to hydrogen peroxide, whereas CAT and GSH-Px break down hydrogen peroxide thus ending the cycle of superoxide neutralization (Michiels et al. 1994). The mRNAs for SOD genes (sod-1 for CuZnSOD and sod-2 for MnSOD) are upregulated after global cerebral ischemia in hippocampal neurons, but processes responsible for SOD activation in the intracellular milieu are mostly unknown (Savitz and Rosenbaum 1999).

IT can be induced by exposing animals or cells to diverse types of chemical and physical stimuli. Ionizing radiation (IR) is a physical stressor, which is able to selectively damage or kill primarily dividing cells and therefore is often used in neuroscience as a tool to stop cell proliferation (Raber et al. 2004; Hellström et al. 2009). The interaction of IR with living cells results in a variety of changes depending on the absorbed dose and the dose rate, the duration of exposure and the post-exposure interval, and the susceptibility of tissues to radiation. The sensitivity of cells to IR also depends on the rate of differentiation and accompanying factors of the tissue as well as on the efficiency of the intrinsic antioxidative defense systems (Manda and Reiter 2010).

The aim of our study was to test the efficacy of IR as Ipre-C in a rat four vessel occlusion model. In the available literature, we have not found any study devoted to this question. To detect neuropathological changes after ischemia we used Fluoro-Jade B (FJB) labeling, as a marker of dying, apoptotic and necrotic neurons (Schmued et al. 1997). Additionally, we assessed whether the salvaged CA1 neurons maintain their function in learning and memory. Our results indicate beneficial effects of IR as a method of inducing IT, which has not been reported before. Radiotherapy using various doses of IR is widely used in treating cancer. However, one of the lingering problems of radiotherapy is the decreased radiosensitivity of cancer cells in the hypoxic areas of the tumour. An additional significance of our results is that they may explain the mechanisms underlying the observed low radiosensitivity of these cells.

\section{Materials and Methods}

\section{Animal model and experimental design}

Forty-six adult male albino Wistar rats (mean body weight of $300 \pm 50 \mathrm{~g}$ ) were used in the experiment. Rats were maintained on LD 12:12 light regimen and given food and water ad libitum. The experiments were performed in accordance with European Community's legislation. The Ethics Committee at the Faculty of Science UPJS in Kosice as well as the State Veterinary and Alimentary Administration of the Slovak Republic approved the experiments. The animals were divided in the following experimental groups: 1) rats exposed to $8 \mathrm{~min}$ of ischemia (I8', $n=7), 2$ ) rats exposed to ischemia and previously irradiated with a dose of $10 \mathrm{~Gy}$ (10 Gy I8', $n=8), 20$ Gy (20 Gy I8', $n=7), 30$ Gy (30 Gy I8', $n=7)$ and 50 Gy (50 Gy I8, $n=7)$ and 3) sham-irradiated controls without ischemia $(C, n=10)$. The experimental protocol is shown in Figure 1.

\section{Irradiation procedure}

On day 1 the animals were cranially irradiated with gamma rays at doses of $10,20,30$ or $50 \mathrm{~Gy}$ as pre-C. The rest of the body was shielded with a $7 \mathrm{~cm}$-thick lead layer. Irradiation of animals was carried out in the irradiation facility Chisostat (Chirana, Prague, Czech Republic), equipped with a source of gamma-rays (60-Co). The animals were maintained under anaesthesia with chloral hydrate $(300 \mathrm{mg} / \mathrm{kg}$, i.p.) during irradiation. The controls were manipulated in the same way, with the exception of irradiation.

\section{Transient forebrain ischemia}

Two days after irradiation transient brain ischemia was induced using the standard four-vessel occlusion model (Pulsinelli and Brierley 1979) as subsequently modified (Schmidt-Kastner et al. 1989). Briefly, on day 3 both vertebral arteries were irreversibly occluded by electrocoagulation through the alar foramina under anaesthesia with chloral hydrate $(300 \mathrm{mg} / \mathrm{kg}$, i.p.). On day 4 both common carotid arteries were occluded by small atraumatic clips after an- 


\begin{tabular}{|c|c|c|c|c|c|c|c|}
\hline \multirow{3}{*}{ Group } & \multicolumn{7}{|c|}{ Procedure } \\
\hline & $\begin{array}{l}\text { irradiation } \\
(10,20,30,50 \mathrm{~Gy}) \\
\text { chloralhydrate } \\
(300 \mathrm{mg} / \mathrm{kg}) \text { i.p. }\end{array}$ & & $\begin{array}{l}\text { cauterization } \\
\text { of vertebral arteries } \\
\text { chloralhydrate } \\
(300 \mathrm{mg} / \mathrm{kg}) \text { i.p. }\end{array}$ & $\begin{array}{l}\text { occlusion of carotids } \\
\text { ( } 8 \mathrm{~min} \text { ) } \\
2,5 \% \text { halothane }\end{array}$ & & MWM 2x & $\begin{array}{l}\text { MWM } 1 x \text {, perfusion } \\
\text { and fixation } \\
\text { chloralhydrate } \\
(300 \mathrm{mg} / \mathrm{kg})\end{array}$ \\
\hline & 1 & 2 & 3 & $\begin{array}{l}4 \\
\text { day }\end{array}$ & $5|6| 7|8| 9 \mid$ & $9 \mid$ & 11 \\
\hline $\begin{array}{l}\text { pre-C+ischemia } \\
(n=29)\end{array}$ & $\checkmark$ & & $\checkmark$ & $\checkmark$ & & & \\
\hline $\begin{array}{l}\text { ischemia } \\
(n=7)\end{array}$ & $X$ & & $\checkmark$ & $\checkmark$ & & $\sqrt{ }$ & $\checkmark$ \\
\hline $\begin{array}{l}\text { control } \\
(n=10)\end{array}$ & $X$ & & $X$ & $X$ & & $\checkmark$ & \\
\hline
\end{tabular}

Figure 1. Experimental protocol. Procedures, which individual experimental groups of animals underwent $(\checkmark)$ or did not (X). Experimental groups: group exposed to ionizing radiation as preconditioning (pre-C) applied 2 days before ischemia, group exposed only to ischemia, control group. All rats were trained and tested in Morris water maze (MWM). For a more detailed description of this protocol, see Materials and Methods.

aesthesia with $2.5 \%$ halothane. Before the carotid occlusion, the halothane was removed and the clips were placed on the carotids just at the moment of anaesthetic fade-out. After 8 min of bilateral carotid occlusion, blood flow was restored by releasing the clips. Normothermic conditions during ischemia were monitored by a microthermistor, placed deep in the ear and maintained at approximately $37^{\circ} \mathrm{C}$ using a homoeothermic blanket. The severity of ischemia was judged by neurological investigation. Criteria for forebrain ischemia were loss of the righting reflex, mydriasis and paw extension. Only animals showing these symptoms were considered to have met the criteria for adequate ischemia (Pulsinelli et al. 1982).

\section{Perfusion and fixation}

The animals were killed 7 days after ischemia by transcardiac perfusion performed under deep anaesthesia (chloral hydrate, $400 \mathrm{mg} / \mathrm{kg}$, i.p.). Perfusion via the left ventricle started with a wash of blood vessels with $300 \mathrm{ml}$ of $0.9 \%$ $\mathrm{NaCl}$. Brains were perfused and fixed with $300 \mathrm{ml}$ of $4 \%$ $(\mathrm{w} / \mathrm{v})$ paraformaldehyde solution in phosphate-buffered saline, removed and postfixed overnight in the same fixative prior to vibratome sectioning. Thirty-three $\mu \mathrm{m}$ coronal sections of the brain were prepared at the level of bregma $-3.3 \pm 0.2 \mathrm{~mm}$.

\section{FJB staining}

The sections were mounted on $2 \%$ gelatin-coated slides and then dried on a slide warmer at $50^{\circ} \mathrm{C}$ for $30 \mathrm{~min}$. The slides were then immersed in the solution containing $1 \%$ sodium hydroxide in $80 \%$ alcohol for $5 \mathrm{~min}$. This was followed by $2 \mathrm{~min}$ in $70 \%$ alcohol and $2 \mathrm{~min}$ in distilled water. The slides were then transferred to the solution of $0.06 \%$ potassium permanganate for $10 \mathrm{~min}$, and subsequently rinsed in distilled water for $2 \mathrm{~min}$. After $20 \mathrm{~min}$ in the staining solution, containing $0.0004 \%$ FJB dye (Histo-Chem Inc., Jefferson, USA), the slides were rinsed three times for 1 minute in distilled water. Excess water was removed by briefly (about $15 \mathrm{~s}$ ) draining the slides vertically on a paper towel. The slides were then placed on a slide warmer (approximately $50^{\circ} \mathrm{C}$ ) until they were fully dry (5-10 $\mathrm{min})$. The dry slides were cleared by immersion in xylene for at least a minute before coverslipping with DPX (Fluka or Sigma). The slides were examined using an Olympus BX 51 fluorescent microscope with a digital camera DP 50.

\section{Behavioural analysis}

To determine the effect of ischemia on hippocampal-dependent learning and to assess the functionality of the surviving CA1 neurons, we subjected groups with $8 \mathrm{~min}$ of ischemia with and without pre-C to Morris water maze (MWM) test. Water maze training apparatus with an escape platform in the opaque water was prepared according to Morris (1984).

\section{Water maze training procedure}

On the $6^{\text {th }}$ day after ischemia each rat underwent 2 training trials, followed the next day by a probe trial. On each training 
trial, a rat was placed in the water facing the same place at the edge of the pool. The rat was allowed $60 \mathrm{~s}$ to locate the platform. If after this period it did not find the escape platform, it was guided there by the experimenter and allowed to remain on the platform for $10 \mathrm{~s}$. The inter-trial interval for each subject was $5 \mathrm{~min}$, during which the rat was returned to its home cage. In the probe trial on the second day, all rats started from the same start position, namely opposite the quadrant where the submerged escape platform had been positioned during the test. The escape latency for each subject (the time the subject required to locate the hidden platform after being released) was measured. The maximal escape latency value was set at $60 \mathrm{~s}$.

\section{Cell counts and statistical analysis}

Neuronal cell count was performed using Image tool software (UTHSCSA, San Antonio, USA). The counting of cells was done by a researcher unaware of the treatment condi- tions. Neurons were counted in the middle of the linear part of the CA1 field in eight different sections from each animal and expressed per $1 \mathrm{~mm}$ of the hippocampal CA1 region. Data were analyzed by ANOVA followed by TukeyKramer's post-hoc test and the unpaired t-test. Differences were considered significant at $p<0.05$.

\section{Results}

Degenerated pyramidal neurons, visualized by FJB, show the damage of the hippocampal CA1 region 7 days after $8 \mathrm{~min}$ of ischemia (Figure $\left.2 \mathrm{~A}, \mathrm{~A}^{\prime}\right)$. Figure 2 shows the influence of $30 \mathrm{~Gy}\left(\mathrm{~B}, \mathrm{~B}^{\prime}\right)$ and $50 \mathrm{~Gy}\left(\mathrm{C}, \mathrm{C}^{\prime}\right)$ doses of IR, applied two days before the short-term ischemia, on the survival of pyramidal neurons in the CA1 region. After ischemia without pre-C almost $50 \%$ of the CA1 pyramidal neurons were lost to degeneration $(145.93 \pm 8.7 \mathrm{FJB}$-positive cells/mm; mean \pm SEM; according to our previous results (Burda et al. 2005)

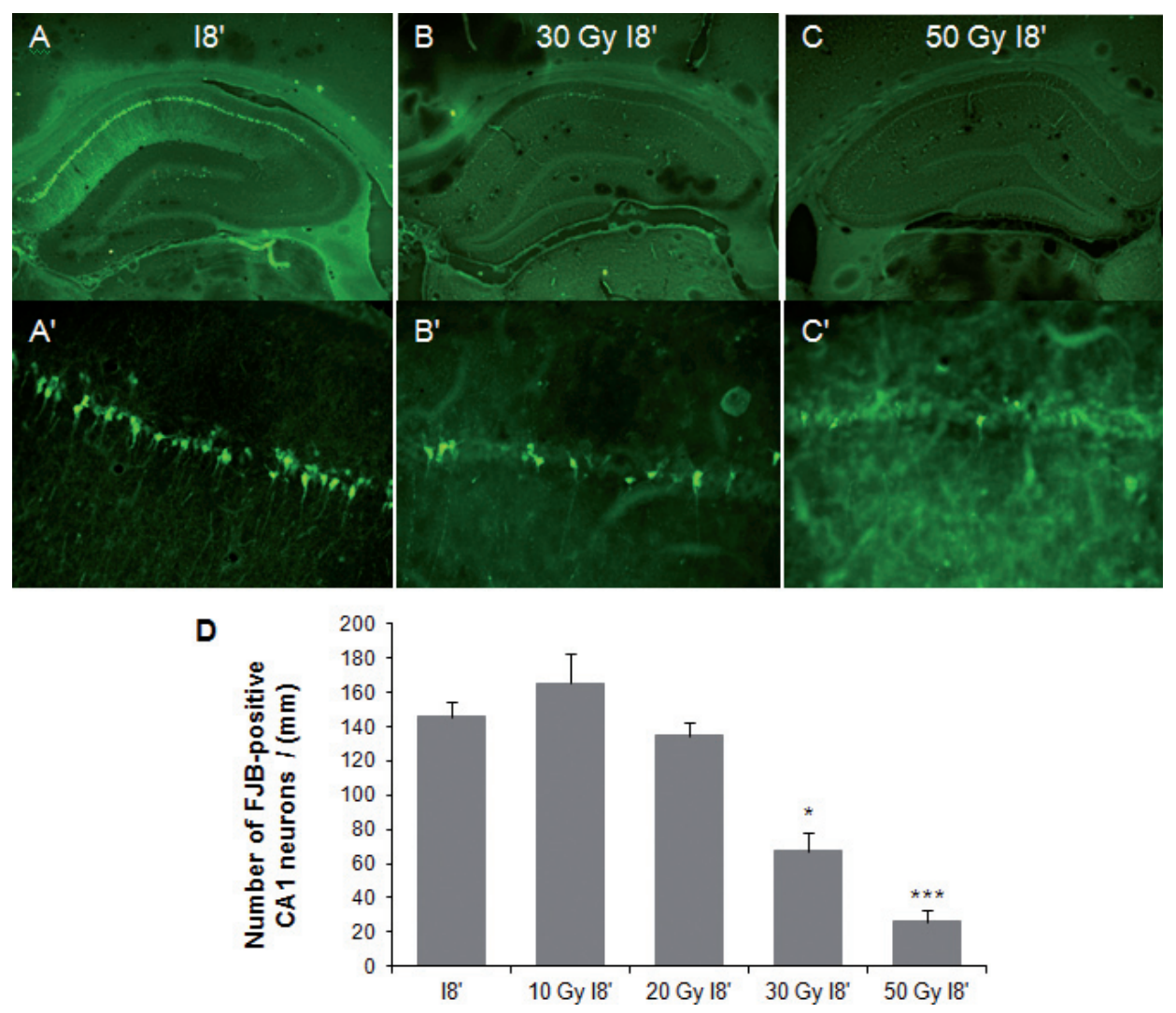

Figure 2. Representative photomicrographs of neurodegeneration in the hippocampal CA1 region visualized by Fluoro Jade B (FJB) staining. A, A'. Group of animals with $8 \mathrm{~min}$ of ischemia (I8'). B, B'. Group of animals with 30 Gy dose preconditioning applied 2 days before $8 \mathrm{~min}$ of ischemia (30 Gy I8'). C, C'. Group of animals with 50 Gy dose preconditioning applied 2 days before 8 min of ischemia (50 Gy I8'). D. Effect of $8 \mathrm{~min}$ of ischemia with or without preconditioning on FJB-positivity in the rat hippocampal CA1 field. Rats with preconditioning were subjected to: $10,20,30$ or $50 \mathrm{~Gy}$ of gamma rays applied 2 days before ischemia. Results are expressed as mean \pm SEM. ${ }^{*} p<0.05,{ }^{* * *} p<0.001$ versus ischemic group (I8'). Magnification $\times 40(\mathrm{~A}, \mathrm{~B}, \mathrm{C})$ and $\times 400\left(\mathrm{~A}^{\prime}, \mathrm{B}^{\prime}, \mathrm{C}^{\prime}\right)$. 
the $100 \%$-value was set to $292.43 \pm 27.6 \mathrm{cells} / \mathrm{mm})$. However, using radiation doses of at least $20 \mathrm{~Gy}$ before ischemia, a decreasing trend of the CA1 neuronal degeneration was observed (Figure 2D). The decrease of FJB-positive cells was significant when the doses of $30 \mathrm{~Gy}(p<0.05)$ and $50 \mathrm{~Gy}(p<$ 0.001 ) were used as pre-C. In addition, no FJB-positivity was detected if only irradiation without ischemia was applied.

The best neuroprotection was observed after the application of the highest dose of radiation. When rats were exposed to the pre-C of $50 \mathrm{~Gy}$, only $9 \%$ (26.28 \pm 7.1 FJB-positive cells $/ \mathrm{mm}$ ) of neurons succumbed to neurodegeneration. When rats were exposed to $30 \mathrm{~Gy}, \mathrm{FJB}$-positivity reached $23.1 \%(67.54 \pm 10.2$ cells $/ \mathrm{mm})$. In the case of $20 \mathrm{~Gy}$ it was $46 \%(134.47 \pm 8.2 \mathrm{cells} / \mathrm{mm})$ and for $10 \mathrm{~Gy}$ it was $56.5 \%$ $(165.19 \pm 17.7$ cells $/ \mathrm{mm})$. In the control group no neurons in the CA1 region of the hippocampus were FJB-positive.

Using the standard Morris water maze we assessed the ability of animals to localize and remember the platform hidden under the water surface. Eight min of ischemia significantly increased the time needed to identify the hidden platform in the second training trial on the first day of the test, as well as on the probe trial on the second day $(p<0.01)$ when compared to the intact controls. Latency times on the second day were shortened proportionally to the radiation dose: 10 Gy $(p<0.001), 20$ Gy $(p<0.01), 30$ Gy $(p<0.05)$ and $50 \mathrm{~Gy}$ (no significant difference) when compared to the intact controls. Dose of $50 \mathrm{~Gy}$ significantly shortened latency times on the second day $(p<0.01)$ compared to the ischemic group. Our results indicate that a certain dose of gamma radiation used as pre- $\mathrm{C}$ can not only induce IT and thus allow the CA1 pyramidal neurons to survive ischemia, but the surviving neurons maintain their function, so that cognitive ability remains close to its normal level (Figure 3).

In order to determine whether the number of FJB-positive CA1 neurons is related to the time needed to localize the platform in the MWM in the $2^{\text {nd }}$ day session, these two parameters were correlated. A highly significant correlation coefficient of 0.9678 was calculated $(p<0.01)$. The shape

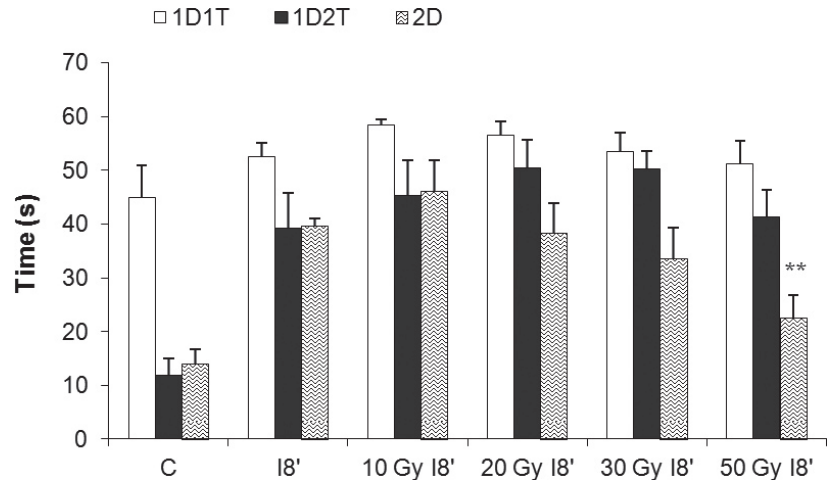

Figure 3. Spatial learning in Morris's water maze (1D1T, $1^{\text {st }}$ day $1^{\text {st }}$ session; $1 \mathrm{D} 2 \mathrm{~T}, 1^{\text {st }}$ day $2^{\text {nd }}$ session; $2 \mathrm{D}, 2^{\text {nd }}$ day probe) expressed as the average times needed to localize the platform. Experimental groups: C, control group; I8, group exposed to $8 \mathrm{~min}$ of ischemia; 10 Gy I8', 20 Gy I8', 30 Gy I8', 50 Gy I8', groups exposed to 10, 20, 30 and $50 \mathrm{~Gy}$ of ionizing radiation, correspondingly, as preconditioning 2 days before ischemia. Results are expressed as mean \pm SEM. ${ }^{* *} p<0.01$ versus ischemic group (I8').

of the relationship between the two parameters was tested calculating the parameters of a linear regression model. The validity of this model was proved with a statistically high reliability (Figure 4).

\section{Discussion}

It is well established that IT can be induced by exposing animals to diverse types of endogenous and exogenous stimuli that are not necessarily hypoxic or ischemic in nature. This is confirmed by many studies, where different chemical and physical stimuli were used, e.g.: sympathetic stimulation (Ravingerova et al. 2002), administration of 3-nitropropionic acid (Kuroiwa 2000), bradykinine (Danielisova et al. 2009) or kainate (Nagy et al. 2011), application of hypothermia

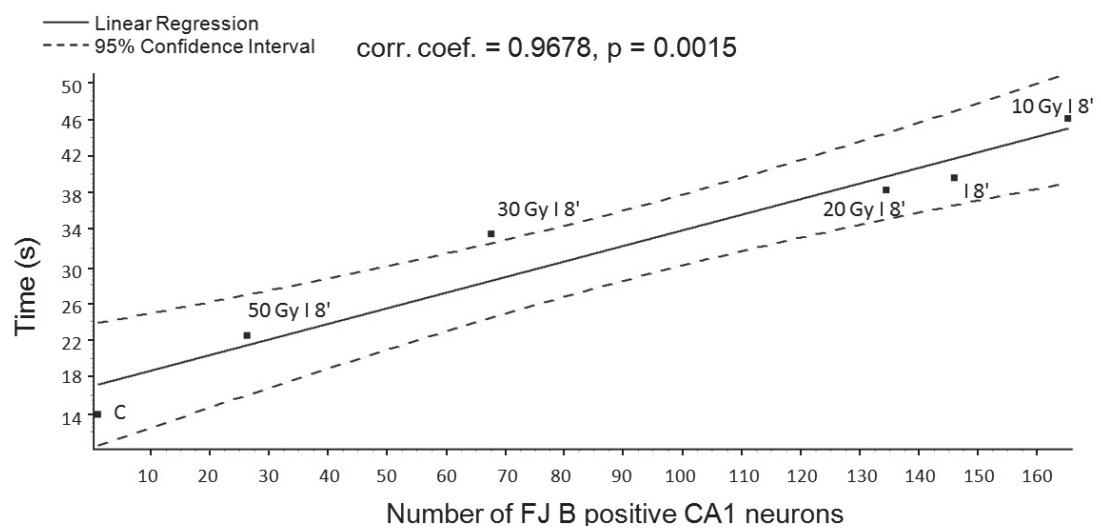

Figure 4. Linear regresion model of the dependance of the time needed to find the hidden platform (ordinate) on the number of Fluoro Jade B (FJB)-positive CA1 neurons. $\mathrm{C}$, control group; I8', group exposed to $8 \mathrm{~min}$ of ischemia; 10 Gy I8, 20 Gy I8', 30 Gy I8, 50 Gy I8', groups exposed to $10,20,30$ and $50 \mathrm{~Gy}$ of ionizing radiation, correspondingly, as preconditioning 2 days before ischemia. The broken lines denote the confidence area for the regression line $(p<0.05)$. 
(Obrenovitch 2008), hyperthermia (Nishio et al. 2000) or transcranial magnetic stimulation (Fujiki et al. 2003).

In our earlier experiments it has been shown, that a $5 \mathrm{~min}$ ischemia causes the degeneration of almost one half of the neurons in the CA1 region of the hippocampus, a $10 \mathrm{~min}$ ischemia kills $72 \%$ of these neurons and an ischemia lasting 15 min causes an almost total destruction of neurons in this region (Burda et al. 2005).

If we applied $5 \mathrm{~min}$ of ischemia and two days of reperfusion, that was later followed by $30 \mathrm{~min}$ of ischemia, we achieved a clear robust protection (96\%) against the degeneration of CA1 neurons. When an injection of norepinephrine was used two days after an $8 \mathrm{~min}$ ischemia, almost $94 \%$ of neurons were saved. A six min ischemia applied 2 days after a $10 \mathrm{~min}$ ischemia rescued $90 \%$ of neurons, and an injection of 3-nitropropionic acid applied two days after a $10 \mathrm{~min}$ ischemia protected $76 \%$ of CA1 neurons (Burda et al. 2005). Using stimuli of suitable intensity and timing, it is possible to avert the delayed neuronal death and turn proapoptotic processes to antiapoptotic. This can serve as evidence that for the activation of the final mechanism of IT the second pathophysiological stress is necessary.

In our current study we used $8 \mathrm{~min}$ of ischemia, which has been proven to destroy almost one half of the neurons in the CA1 region. When animals were irradiated with gamma rays 2 days before ischemia, a remarkable increase of the survival of CA1 neurons was achieved, but this neuroprotective effect was observed only with higher radiation doses. There was a small increase in the number of degenerating cells in rats irradiated with $10 \mathrm{~Gy}$ to $56.5 \%$, which is by $6.6 \%$ higher than the ischemia group. A twenty Gy dose of pre-C resulted in $46 \%$ neurodegeneration, which is by $3.9 \%$ less compared to the ischemia group. An interesting result was obtained after using 30 and $50 \mathrm{~Gy}$ as pre-C: the dose of $30 \mathrm{~Gy}$ saved $26.8 \%$ of cells, thus, FJB-positivity reached only $23.1 \%$ and the dose of 50 Gy was the most effective - only $9 \%$ of CA1 neurons were lost to degeneration, which is by $40.9 \%$ less compared to ischemia group.

Based on these observations we can conclude that IR, when applied in sufficient doses, is able to activate the mechanism of IT and thereby create conditions for the protection of pyramidal neurons against delayed neuronal death following ischemia in the CA1 region.

An increased production of ROS and subsequent oxidative stress probably plays a key role in the induction of delayed neuronal death. Therefore, several authors have focused on monitoring the internal activity of antioxidant enzymes (Danielisova et al. 2009; Nemethova et al. 2010). De novo synthesized proteins, e.g. heat shock proteins (Liu et al. 1993b), Bcl2 (Shimazaki et al. 1994), superoxide dismutase (MnSOD) (Bordet et al. 2000), the pro-survival inhibitorof-apoptosis (IAP) (Tanaka et al. 2004), and probably some others, also contribute to the acquisition of delayed IT. Our current work did not address the molecular mechanisms of IT, but represents another example of a successful induction of IT by other than ischemic stimuli. We confirm the role of repeated stress for the acquisition of complete IT.

Our results, similar to the results of other authors (Gobbo and O'Mara 2004; Bendel et al. 2005; Hartman et al. 2005), also show that selectively vulnerable pyramidal neurons in the CA1 region are important for the cognitive functions such as spatial learning and memory: we observed increased latency times in MWM after $8 \mathrm{~min}$ of ischemia. In animals irradiated 2 days before the ischemic event the latency times on the second day have shortened proportionally to the radiation dose. We found a significant difference between the doses of 10 and $50 \mathrm{~Gy}$. Whereas cognitive function worsened slightly in rats irradiated with $10 \mathrm{~Gy}$ in comparison not only to control but also to the ischemic group without irradiation, in rats irradiated with 50 Gy cognitive function was at the control level.

Results from other experiments also show that pre- or post-C not only increases the survival of neurons, but that the surviving cells maintain their function in learning and spatial memory. We previously observed a significant increase in latency to find the hidden platform in rats after a $10 \mathrm{~min}$ ischemia compared to the intact controls or to animals that experienced postconditioning (Burda et al. 2005). Nagy et al. (2011) also found that the application of post- $\mathrm{C}$ at a suitable time and dose is able to protect structural plasticity and hippocampal function. Raber et al. (2004) found that the functional impairments after cerebral ischemia were exacerbated by a low dose of irradiation ( 5 Gy), which inhibited neurogenesis and worsened the water-maze performance. In our experiment a lower (10 Gy) dose of IR also worsened the performance in MWM and increased the number of degenerating pyramidal neurons, in comparison to control $(p<0.001)$ and ischemic groups. Since a radiation dose of at least 20 Gy was needed to see an improvement in water-maze performance and a decreasing trend in the number of FJB-positive cells, we conclude that for the activation of the mechanism of IT higher doses of IR are necessary.

As a confirmation of a possible causal dependence between the number of intact hippocampal CA1 neurons and cognitive abilities in rats we found a statistically highly significant negative correlation between the number of FJBpositive neurons and learning perfomance in MWM on the second training day.

Our results indicate that gamma radiation used as pre-C can induce IT and thus allow the CA1 pyramidal neurons to survive ischemia. However, our results suggest an even more important thing: if irradiation is used with the aim to kill an undesirable population of cells and we do not kill all of these cells with the first dose, for the surviving cells irradiation becomes sublethal and able to induce tolerance. 
Acquired tolerance will preserve cells against subsequent, even substantially higher doses, and cross tolerance means that cells are protected against a wide range of different lethal agents. Thus, in a broader aspect, our results could also contribute to the elucidation of mechanisms underlying the increase of radioresistance of cancer cells in the potentially ischemic centre of a solid tumour during radiotherapy with fractionated irradiation schedule, as it is often observed (Shimura et al. 2010).

Acknowledgements. The authors gratefully acknowledge the excellent technical assistance of Dana Jurusova. This study is the result of implementation of the project: "New possibilities of preservation of neurons in the process of delayed neuronal death by nonspecific stressors" supported by the Research \& Development Operational Programme funded by the ERDF grant number ITMS 26220220043. The project was also supported by research grants VEGA No. 1/0292/12 and VEGA No. 2/0148/12.

\section{References}

Bendel O., Bueters T., von Euler M., Ögren S. O., Sandin J., von Euler G. (2005): Reappearance of hippocampal CA1 neurons after ischemia is associated with recovery of learning and memory. J. Cereb. Blood Flow Metab. 25, 1586-1595 http://dx.doi.org/10.1038/sj.jcbfm.9600153

Bordet R., Deplanque D., Maboudou P., Puisieux F., Pu Q., Robin E., Martin A., Bastide M., Leys D., Lhermitte M., Dupuis B. (2000): Increase in endogenous brain superoxide dismutase as a potential mechanism of lipopolysaccharide-induced brain ischemic tolerance. J. Cereb. Blood Flow Metab. 20, 1190-1196 http://dx.doi.org/10.1097/00004647-200008000-00004

Burda J., Hrehorovska M., Bonilla L., Cizkova D. (2003): Role of protein synthesis in the ischemic tolerance acquisition induced by transient forebrain ischemia in the rat. Neurochem. Res. 28, 1213-1219 http://dx.doi.org/10.1023/A:1024232513106

Burda J., Matiasova M., Gottlieb M., Danielisova V., Nemethova M., Garcia L., Salinas M., Burda R. (2005): Evidence for a role of second pathophysiological stress in prevention of delayed neuronal death in the hippocampal CA1 region. Neurochem. Res. 30, 1397-1405 http://dx.doi.org/10.1007/s11064-005-8510-z

Danielisova V., Gottlieb M., Nemethova M., Kravcukova P., Domorakova I., Mechirova E., Burda J. (2009): Bradykinin postconditioning protects pyramidal CA1 neurons against delayed neuronal death in rat hippocampus. Cell. Mol. Neurobiol. 29, 871-878 http://dx.doi.org/10.1007/s10571-009-9369-3

Fujiki M., Kobayashi H., Abe T., Kamida T. (2003): Repetitive transcranial magnetic stimulation for protection against delayed neuronal death induced by transient ischemia. J. Neurosurg. 99, 1063-1069 http://dx.doi.org/10.3171/jns.2003.99.6.1063

Gobbo O. L., O'Mara S. M. (2004): Impact of enriched environment housing on brain-derived neurotrophic factor and on cognitive performance after a transient global ischemia. Behav. Brain Res. 152, 231-241 http://dx.doi.org/10.1016/j.bbr.2003.10.017

Hartman R. E., Lee J. M., Zipfel G. J., Wozniak D. F. (2005): Characterizing learning deficits and hippocampal neuron loss following transient global cerebral ischemia in rats. Brain Res. 1043, $48-56$ http://dx.doi.org/10.1016/j.brainres.2005.02.030

Hellström N. A. K., Björk-Eriksson T., Blomgren K., Kuhn G. (2009): Differential recovery of neural stem cells in the subventricular zone and dentate gyrus after ionizing radiation. Stem Cells. 27, 634-641 http://dx.doi.org/10.1634/stemcells.2008-0732

Kirino T. (1982): Delayed neuronal death in the gerbil hippocampus following ischemia. Brain Res. 239, 57-69 http://dx.doi.org/10.1016/0006-8993(82)90833-2

Kirino T. (2002): Ischemic tolerance. J. Cereb. Blood Flow Metab. 22, 1283-1296 http://dx.doi.org/10.1097/00004647-200211000-00001

Kuroiwa T., Yamada I., Endo S., Hakamata Y., Ito U. (2000): 3-Nitropropionic acid preconditioning ameliorates delayed neurological deterioration and infarction after transient focal cerebral ischemia in gerbils. Neurosci. Lett. 283, 145-148 http://dx.doi.org/10.1016/S0304-3940(00)00937-X

Lehotsky J., Burda J., Danielisova V., Gottlieb M., Kaplan P., Saniova B. (2009): Ischemic tolerance: the mechanisms of neuroprotective strategy. Anat Rec 292, 2002-2012 http://dx.doi.org/10.1002/ar.20970

Liu X. H., Kato H., Nakata N., Kogure K., Kato K. (1993a): An immunohistochemical study of copper/zinc superoxide dismutase and manganese superoxide dismutase in rat hippocampus after transient cerebral ischemia. Brain Res. 625, 29-37 http://dx.doi.org/10.1016/0006-8993(93)90134-9

Liu Y., Kato H., Nakata N., Kogure K. (1993b): Temporal profile of heat shock protein 70 synthesis in ischemic tolerance induced by preconditioning ischemia in rat hippocampus. Neuroscience 56, 921-927 http://dx.doi.org/10.1016/0306-4522(93)90138-6

Manda K., Reiter R. J. (2010): Melatonin maintains adult hippocampal neurogenesis and cognitive function after irradiation. Prog. Neurobiol. 90, 60-68 http://dx.doi.org/10.1016/j.pneurobio.2009.10.019

McDonald R. L., Stoodley M. (1998): Pathophysiology of cerebral ischemia. Neurol. Med. Chir. 38, 1-11 http://dx.doi.org/10.2176/nmc.38.1

Michiels C., Reas M., Toussaint O., Remacle J. (1994): Importance of Se-glutathione peroxidase, catalase, and $\mathrm{Cu} / \mathrm{Zn}$-SOD for cell survival against oxidative stress. Free Radic. Biol. Med. 17, 235-248 http://dx.doi.org/10.1016/0891-5849(94)90079-5

Morris R. (1984): Developments of a water-maze procedure for studying spatial learning in the rat. J. Neurosci. Methods 11, $47-60$ http://dx.doi.org/10.1016/0165-0270(84)90007-4

Murry C. E., Jennings R. B., Reimer K. A. (1986): Preconditioning with ischemia: A delay of lethal cell injury in ischemic myocardium. Circulation 74, 1124-1136 http://dx.doi.org/10.1161/01.CIR.74.5.1124 
Nagy D., Kocsis K., Fuzik J., Marosi M., Kis Z., Teichberg V. I., Toldi J., Farkas T. (2011): Kainate postconditioning restores LTP in ischemic hippocampal CA1: Onset-dependent second pathophysiological stress. Neuropharmacology 6, 1026-1032 http://dx.doi.org/10.1016/j.neuropharm.2011.07.005

Nemethova M., Danielisova V., Gotlieb M., Kravcukova P., Burda J. (2010): Ischemic postconditioning in the rat hippocampus: mapping of proteins involved in reversal of delayed neuronal death. Arch. Ital. Biol. 148, 23-32

Nishio S., Yunoki M., Chen Z.F., Anzivino M. J., Lee K. S. (2000): Ischemic tolerance in the rat neocortex following hypothermic preconditioning. J. Neurosurg. 93, 845-851 http://dx.doi.org/10.3171/jns.2000.93.5.0845

Obrenovitch T. P. (2008): Molecular physiology of preconditioning induced brain tolerance to ischemia. Physiol. Rev. 88, 211-247 http://dx.doi.org/10.1152/physrev.00039.2006

Pulsinelli W. A., Brierley J. B. (1979): A new model of bilateral hemispheric ischemia in the unanesthetized rat. Stroke 10, 267-272 http://dx.doi.org/10.1161/01.STR.10.3.267

Pulsinelli W. A., Brierley J. B., Plum F. (1982): Temporal profile of neuronal damage in a model of transient forebrain ischemia. Ann. Neurol. 11, 491-498 http://dx.doi.org/10.1002/ana.410110509

Raber J., Fan Y., Matsumori Y., Liu Z., Weinstein P. R., Fike J. R., Liu J. (2004): Irradiation attenuates neurogenesis and exacerbates ischemia-induced deficits. Ann. Neurol. 55, 381-389 http://dx.doi.org/10.1002/ana.10853

Ravingerova T., Pancza D., Ziegelhoffer A., Styk J. (2002): Preconditioning modulates susceptibility to ischemia-induced arrhythmias in the rat heart: the role of alpha-adrenergic stimulation and K (ATP) channels. Physiol. Res. 51, 109-119

Riksen N. P., Smits P., Rongen G. A. (2004): Ischaemic preconditioning: from molecular characterisation to clinical application-part, I. Neth. J. Med. 62, 353-363
Savitz S. I., Rosenbaum D. M. (1999): Gene expression after cerebral ischemia. Neuroscientist 5, 238-253 http://dx.doi.org/10.1177/107385849900500413

Schmidt-Kastner R., Paschen W., Ophoff B. G., Hossmann K. A. (1989): A modified four-vessel occlusion model for inducing incomplete forebrain ischemia in rats. Stroke 20, 938-946 http://dx.doi.org/10.1161/01.STR.20.7.938

Schmued L. C., Albertson C., Slikker W. Jr. (1997): Fluoro-Jade: a novel fluorochrome for the sensitive and reliable histochemical localization of neuronal degeneration. Brain Res. 751, 37-46 http://dx.doi.org/10.1016/S0006-8993(96)01387-X

Schurr A., Reid K. H., Tseng M. T., West C., Rigor B. M. (1986): Adaptation of adult brain tissue to anoxia and hypoxia in vitro. Brain Res. 374, 244-248 http://dx.doi.org/10.1016/0006-8993(86)90418-X

Shimazaki K., Ishida A., Kawai N. (1994): Increase in bcl-2 oncoprotein and the tolerance to ischemia-induced neuronal death in the gerbil hippocampus. Neurosci. Res. 20, 95-99 http://dx.doi.org/10.1016/0168-0102(94)90026-4

Shimura T., Kakuda S., Ochiai Y., Nakagawa H., Kuwahara Y., Takai Y., Kobayashi J., Komatsu K., Fukumoto M. (2010): Acquired radioresistance of human tumor cells by DNA-PK/ AKT/GSK3 $\beta$-mediated cyclin D1 overexpression. Oncogene 29, 4826-4837 http://dx.doi.org/10.1038/onc.2010.238

Tanaka H., Yokota H., Jover T., Cappuccio I., Calderone A., Simionescu M., Bennett M. V., Zukin R. S. (2004): Ischemic preconditioning: neuronal survival in the face of caspase) 3 activation. J. Neurosci. 24, 2750-2759 http://dx.doi.org/10.1523/JNEUROSCI.5475-03.2004

Received: January 17, 2014

Final version accepted: June 30, 2014

First published online: July 17, 2014 